\title{
Comunicación y buen vivir. La crítica descolonial y ecológica a la comunicación para el desarrollo y el cambio social
}

\section{Alejandro Barranquero-Carretero ${ }^{1}$ Chiara Sáez-Baeza²}

Recibido: 2014-05-16

Enviado a pares: 2014-05-18
Aprobado por pares: 2014-07-22

Aceptado: 2014-08-06

DOI: 10.5294/pacla.2015.18.1.3

Para citar este artículo / To reference this article / Para citar este artigo Barranquero-Carretero, A. Sáez-Baeza, Ch. Marzo de 2015. La crítica descolonial y ecológica a la comunicación para el desarrollo y el cambio social. Palabra Clave 18(1), 41-82. DOI: 10.5294/pacla.2015.18.1.3

\section{Resumen}

La cosmovisión del buen vivir promueve un giro biocéntrico y descolonial con respecto a las nociones de comunicación para el desarrollo y para el cambio social. Este artículo plantea un recorrido por la historia de la disciplina con el objeto de incorporar los nuevos debates surgidos en torno al posdesarrollo y la ecología crítica, especialmente a partir de la revalorización de los legados culturales sostenibles silenciados por el binomio modernidad/colonialidad.

\section{Palabras clave}

Comunicación, comunicación espacial, comunicación y desarrollo, desarrollo sostenible, colonialismo (Fuente: Tesauro de la Unesco). 


\section{Communication and good living. The decolonial and ecological critique to communication for development and social change}

\section{Abstract}

The world view of living well encourages a biocentric and decolonial change of direction in the ideas on communication for development and for social change. This article provides an overview of the history of the discipline in an effort to include the new debates on post-development and critical ecology, particularly from the standpoint of re-evaluating the sustainable cultural legacies silenced by the modernity/coloniality perspective.

\section{Keywords}

Communication, spatial communication, communication and development, sustainable development, colonialism (Source: Unesco Thesaurus). 


\section{Comunicação e bom viver. A crítica descolonial e ecológica à comunicação para o desenvolvimento e a mudança social}

\section{Resumo}

A cosmovisão do bom viver promove um giro biocêntrico e descolonial a respeito das noções de comunicação para o desenvolvimento e para a mudança social. Este artigo propõe um percorrido pela história da disciplina com o objetivo de incorporar os novos debates surgidos ao redor do pós-desenvolvimento e da ecologia crítica, especialmente a partir da revalorização dos legados culturais sustentáveis, silenciados pelo binômio modernidade e colonialidade.

\section{Palavras-chave}

Comunicação, comunicação espacial, comunicação e desenvolvimento, desenvolvimento sustentável, colonialismo (Fonte: Tesauro da Unesco). 


\section{Desde la comunicación para el desarrollo a la comunicación para el cambio social}

En el concepto de desarrollo que aún prevalece en las políticas de cooperación y los imaginarios sociales se sedimentan los diferentes énfasis y significados que esta "idea-faro" (Sachs, 1992) ha ido acumulando a lo largo de la historia. Este emerge y adquiere legitimidad vinculado al denominado punto cuarto del Discurso sobre el Estado de la Unión de Harry Truman (1949), que dividió el mundo entre naciones "desarrolladas" y "subdesarrolladas", y sumió a todo lo que no era Occidente en un hipotético estado de "subdesarrollo", o una "condición indigna" de la cual se debe "escapar" (Esteva, 1992: 7). Durante la segunda mitad del siglo XX, el desarrollo se convirtió en sinónimo de la expansión universal de los valores culturales del Norte, ${ }^{3}$ y en particular del sistema capitalista y su etos en exceso racionalista, productivista y colonizador (Di Filippo, 2007: 149). En este sentido, el concepto reciclaba, por un lado, el espíritu ilustrado y su fe ciega en la razón y el progreso tecnocientífico ilimitado del ser humano a expensas de la naturaleza (siglo XVIII) y, por otro, la misión redentora y adoctrinadora de un Occidente imperialista sobre los pueblos "primitivos" e "incivilizados” del sur del planeta (siglo XIX). ${ }^{4}$ Esta concepción ha marcado una particular geometría del desarrollo en la configuración del sistema de cooperación internacional (Usaid, IICA, BM, FAO, PNUD, etc.), que justifica la superioridad de los países más ricos y su modelo normativo de intervención sobre las áreas "subdesarrolladas", de acuerdo con sus particulares intereses económicos y geoestratégicos (Shah \& Wilkins, 2004: 397).

En paralelo al nacimiento de la cooperación, el desarrollo se fue instituyendo como objeto de estudio de las ciencias sociales y, en particular, de lo que en economía y sociología se conoce, desde los años cincuenta, como teorías de la modernización, que fueron progresivamente desacreditadas en

3 A fin de organizar la argumentación, a lo largo del artículo se emplean conceptos como ciencia moderna o Norte/Sur a modo de "tipos-ideales" weberianos. Estos no deben ser interpretados como si fuesen entes unificados y homogéneos, dado que en todos ellos existen contradicciones y complejidades, como desarrollaremos al final del artículo.

4 Otras bases históricas de la idea de desarrollo se pueden encontrar en los ideales de tutela y salvación de las religiones monoteístas, así como en la concepción evolucionista de un avance natural progresivo hacia estadios más perfectos. Estos debates se recogen en clásicos como Sztompka (1995) o Rist (1997). 
razón de su carácter etnocéntrico y ahistórico (Cardesín, 1997: 147-151), así como por tratarse de "un funcionalismo y un conductismo de origen estadounidense interesados en el diseño de iniciativas de política exterior a fin de establecer tabiques geopolíticos contra el bloque soviético durante la Guerra Fría” (Shah, 2010: 1). ${ }^{5}$ En el naciente campo de la comunicación, la modernización fue entendida como el empleo persuasivo de los medios de la época -en especial, radio y prensa- a fin de generar cambios de conducta o incluso eliminar las culturas originarias de las regiones más desfavorecidas -consideradas "barreras" u "obstáculos" al desarrollo-, para embarcarlas en un proceso de imitación de los valores culturales del Norte. En este contexto los medios fueron concebidos como "multiplicadores mágicos" del desarrollo (Shah, 2010), "indicadores" del grado de avance de un país (Schramm, 1964) o instrumentos orientados a la "difusión de innovaciones" (Rogers, 1962), en un proceso secuenciado en etapas hacia un crecimiento económico acelerado y autosostenible (Rostow, 1960).

Al poco de iniciar su andadura, el paradigma de la modernización comenzó a evidenciar profundas carencias y limitaciones, ya que, paradójicamente, contribuía a acentuar la situación de subdesarrollo y dependencia estructural de muchos países. Estas consecuencias han sido calificadas de "maldesarrollo", un concepto que implica "la constatación del fracaso del programa del 'desarrollo", así como el "Mal Vivir que puede observarse en el funcionamiento del sistema mundial y de sus componentes, desde los Estados nacionales a las comunidades locales", de manera que si el desarrollo "implica un elemento normativo (lo deseable), 'maldesarrollo' contiene un componente empírico (lo observable) o incluso crítico (lo indeseable)” (Tortosa, 2009: 68).

Los primeros cuestionamientos llegaron de las propias regiones objeto de las políticas de cooperación: Asia, África y, en especial, Latinoamérica. Sin embargo, la teoría dominante de la comunicación para el desarrollo ha tendido a infravalorar o ignorar estas aportaciones. ${ }^{6}$ De hecho, los

5 La traducción de los textos del inglés es nuestra.

6 Existe una larga tradición de estudios que reclaman la "desoccidentalización” de los estudios mediáticos: Curran \& Park (2000), Gunaratne (2010), Wang (2010), etc. En el caso de la comunicación para el desarrollo, cabe destacar los esfuerzos de Barranquero (2009), Manyozo (2006), Melkote \& Steeves (1991), Riaz \& Pasha (2012) y Wilkins \& Moody (2001). 
principales compendios históricos y metateóricos de estas disciplinas priorizan, desde una perspectiva colonial, la contribución estadounidense y europea, relegando a un segundo plano las aportaciones de otras regiones, consideradas de menor valor, cuando no meras disputas ideológicas o políticas, y, por consiguiente, acientíficas. ${ }^{7}$ Más allá de los desafíos planteados en el continente africano y asiático -bien descritos en Manyozo (2006) o Melkote \& Steeves (1991)-, el aporte de América Latina se ha situado a la vanguardia de la crítica tanto al concepto originario de desarrollo como a la mirada informacional reduccionista de la mass communication research y, por ende, al paradigma modernizador -o Escuela de Bretton Woods,$-{ }^{8}$ aún hegemónicos en las políticas y la planificación del desarrollo, ${ }^{9}$ así como en los principales debates internacionales del área, como es el caso de las Cumbres Mundiales de la Sociedad de la Información de Ginebra (2003) y Túnez (2005) (Hamelink, 2004).

Esta crítica debe enmarcarse en el contexto latinoamericano de la segunda mitad del siglo XX, al que, más allá de las diferencias regionales, podríamos caracterizar de acuerdo con una relación dialéctica entre dependencia y liberación, o lo que es lo mismo, ciclos históricos de violencia y marginación, gobiernos oligárquicos, dictaduras militares, imperialismo y colonialismo, exclusión de los sectores populares, etc., frente a los cuales emergen alternativas de cambio desde el ámbito de la política -revolucionarias (Cuba, 1959) o reformistas (Chile, 1970)-, la religión -teología de la liberación- o los movimientos sociales de carácter obrero, campesino, indigenista o feminista.

En este marco, América Latina se ha destacado por dos contribuciones pioneras. La primera es el camino trazado desde los años cincuenta por las teorías de la dependencia y su crítica a la dominación histórica y estruc-

7 Esto es evidente, en mayor o menor medida, en recuentos históricos de la disciplina como los de Hornik (1988), McAnany (2012), Rogers (1994), Sparks (2007) y, sobre todo, Stevenson (1988). Testimonios interesantes para conocer los intereses económicos, geoestratégicos y militares que determinaron la investigación modernizadora son los de Gilman (2003), Latham (2000), Samarajiwa (1987), Simpson (1993) y Tunstall (1977).

8 La calificación de escuela hace referencia a las aproximaciones que derivaron del Plan Marshall después de la Segunda Guerra Mundial y el establecimiento del Sistema Bretton Woods del Banco Mundial y el Fondo Monetario Internacional en 1944 (Manyozo, 2006).

9 Sobre la influencia del paradigma modernizador, consultar: Fair \& Shah (1997), Servaes (1999, 2012) y Shah (2010). 
tural de los países altamente industrializados, o centrales, sobre los recursos materiales y simbólicos de los "periféricos", un marco que contribuyó a situar la causa del subdesarrollo no en la cultura de las poblaciones del Sur, sino en su relación de dependencia con respecto al Norte. ${ }^{10}$ Por otra parte, desde mediados de los sesenta, y en algunos casos bajo la influencia de las teorías de la dependencia, emergió un núcleo de pensadores críticos en el ámbito de la comunicación, que una década más tarde habría de caracterizarse por una fuerte cohesión con base en lazos de amistad (White, 1989) y su búsqueda de una ciencia comunicacional explícitamente normativa, política y comprometida con el cambio social -o "comunicología de la liberación”, de acuerdo con la expresión de Beltrán (1979)-, entre los que cabe señalar al propio Luis Ramiro Beltrán, a José Marqués de Melo, Juan Díaz Bordenave, Paulo Freire, Mario Kaplún o Antonio Pasquali. A diferencia de la mass communication research y la teoría crítica europea, la "Escuela (Crítica) Latinoamericana de la Comunicación” (Marqués de Melo, 2007) se distinguió por su énfasis en la praxis como eje central para la construcción teórica (Dervin \& Huesca, 1994; Huesca, 2002). Esta concepción estuvo inspirada, en buena medida, por la prolífica e imaginativa práctica comunicacional de los movimientos de base del continente desde mediados del siglo XX: radios sindicales mineras bolivianas, proyectos educomunicativos populares inspirados en la pedagogía crítica de Paulo Freire, radioforums y radioescuelas como los programas de educación a distancia de radio Sutatenza-proyecto ACPO en Colombia, etc. (Beltrán, 1993).

La crítica al imperialismo cultural ${ }^{11}$ dio lugar a que especialistas como Beltrán $(1974,1976)$ o Díaz Bordenave (1976) planteasen severas reservas con respecto al carácter etnocéntrico, economicista y en exceso persuasivo de los primeros programas modernizadores, en razón de su matriz funcionalista y

10 Las teorías de la dependencia emergieron en el círculo de economistas de la Cepal en los años cincuenta y alcanzaron su máximo esplendor en las dos décadas siguientes. El binomio centro-periferia fue propuesto por primera vez por el argentino Raúl Prebisch (1949) en su análisis de las relaciones económicas y comerciales de la posguerra. Estas tesis fueron retomadas por Cardoso y Faletto (1967). Para analizar la vigencia y limitaciones de esta teoría, consultar Beigel (2006).

11 Pese a que en los orígenes de la noción de imperialismo convergen distintas tradiciones epistemológicas y localizaciones (Mattelart, 2013: 206-208), cabe señalar que las tesis tuvieron un desarrollo muy importante en el ámbito latinoamericano por parte de autores como el propio Armand Mattelart, Luis Ramiro Beltrán, Antonio Pasquali, Heriberto Muraro o Rafael Roncagliolo. Sus trabajos fueron el germen de la prolífica reflexión latinoamericana en economía política de la comunicación. 
su tendencia al olvido de la historia, la estructura y el conflicto. En su lugar, pioneros como Paulo Freire (1970) enfatizaron la relación entre comunicación y participación comunitaria, entendidas como un proceso dialógico que conduce a los sujetos a descubrir las condiciones de su opresión y a construir alternativas comunitarias de cambio. El pedagogo brasileño también alentó a dar un giro de $180^{\circ}$ con respecto al carácter exógeno y universal de los primeros esquemas modernizadores o "extensionistas", que proponían un flujo informativo desigual y reproductor de la estructura de poder dominante, articulado desde unos emisores todopoderosos -los medios masivos, los expertos en desarrollo, los educadores, etc.-, hacia aquellos a los que se juzgaba carentes de juicio crítico: las comunidades. En el esquema de Freire, los "oprimidos" pasaron de ser el objeto pasivo de la relación -o el "receptáculo vacío" en el que inocular los valores y comportamientos del Norte (Freire, 1969)-, a convertirse en sujetos activos de su propio devenir.

Estos avances marcaron el inicio del denominado paradigma participativo de la comunicación para el desarrollo, que tuvo una amplia resonancia en el ámbito de las políticas de comunicación y constituyó uno de los ejes centrales del debate más radical y democratizador del campo, que tuvo lugar durante la denominada "década de fuego" de los setenta (Beltrán, 2007) y su hito más significativo, el Informe McBride Un solo mundo, voces múltiples, que llamaba a una "nueva actitud para superar el pensamiento estereotipado y promover una mayor comprensión de la diversidad y la pluralidad, con pleno respeto de la dignidad y la igualdad de los pueblos que viven y actúan de diferentes maneras" (International Commission for the Study of Communication Problems, 1980: 254). ${ }^{12}$ Finalmente, algunos de los impulsores de la modernización, como Everett Rogers (1976), reconocieron la influencia de los debates latinoamericanos, ${ }^{13}$ si bien hay quienes han venido afirmando que la revisión del paradigma dominante no fue más que el modelo difusionista "con nuevos ropajes" (Mansell, 1982: 54).

12 Juan Somavía y Gabriel García Márquez formaron parte de la Comisión McBride, que también tuvo como testigos directos a Antonio Pasquali, Luis Ramiro Beltrán o Héctor Schmucler, entre otros. Revisar al respecto el monográfico especial ( $\left.n^{\circ} 21\right)$ de la publicación Quaderns del CAC.

13 Everett M. Rogers, creador del difusionismo, invitó a Beltrán (1976) y a Díaz Bordenave (1976) a revisar el paradigma dominante de la comunicación para el desarrollo en un número especial de Communication Theory (Rogers, 1976), publicado también como libro por Sage. 
Tras la denominada década perdida del desarrollo, ${ }^{14}$ las propuestas participativas constituyeron la base del nuevo concepto de la comunicación para el cambio social. Esta denominación fue adoptada en el seno de dos vitales reuniones, en Bellagio (1997) y Cape Town (1998), ${ }^{15}$ en las que algunos de los profesionales y académicos más relevantes de la tan cuestionada comunicación para el desarrollo adoptaron una nueva definición y orientación para la disciplina. La nueva hoja de ruta desestimaba la noción colonial y economicista del desarrollo, al tiempo que definía un programa común para el siglo XXI, basado en un "proceso de diálogo público y privado a partir del cual las gentes deciden quiénes son, cuáles son sus aspiraciones, qué es lo que necesitan y cómo pueden organizarse colectivamente para alcanzar sus metas y mejorar sus vidas" (Gray-Felder \& Deane, 1999: 8).

Desde entonces, se han dado numerosos avances hacia la consolidación de la disciplina, como la publicación de los primeros readers y antologías (Gumucio-Dagron, 2001; Gumucio-Dagron \& Tufte, 2006; Wilkins, Tufte \& Obregón, 2014), la celebración de un importante encuentro a nivel mundial (el I Congreso Mundial de Comunicación para el Desarrollo, Roma, 2006) 16 $^{16}$ o la formulación de criterios pedagógicos (Red Universitaria de Comunicación para el Cambio Social, 2005). ${ }^{17}$ En el plano epistemológico, el nuevo concepto supuso avances significativos en relación con el desarrollo, puesto que, frente a su dirección universalista y centrada en lo económico, la nueva expresión apunta a la "multiplicidad" (Servaes, 1999) de procesos dialógicos que pueden contribuir a la consecución de mejoras desde la valoración de los contextos históricos, las singularidades locales y perspectivas "centradas en lo cultural” (Dutta, 2011).

14 Denominación habitual para describir las crisis económicas latinoamericanas de los ochenta como consecuencia de las políticas de ajuste impuestas por organismos como el Banco Mundial o el Fondo Monetario Internacional. Se encuentra, por ejemplo, en Melkote \& Steeves (1991: 377).

15 Este concepto-programa fue asumido y promocionado por la Rockefeller Foundation y el Consorcio de la Comunicación para el Cambio Social, con la financiación de la primera. También ha sido abanderado por muchas agencias, ONG y movimientos sociales a lo largo del planeta.

16 El Congreso de Roma fue organizado conjuntamente por la FAO, el Banco Mundial y la Iniciativa de la Comunicación (2007), "organizaciones que tienen diferente naturaleza y poco en común en su enfoque sobre el desarrollo" (Gumucio-Dagron, 2006).

17 El primer encuentro de la Red tuvo lugar en Filipinas en 2005, auspiciado por el Colegio de Comunicación para el Desarrollo de la Universidad de Filipinas en Los Baños, Manila. 
Sin embargo, más allá de la definición institucional antes señalada, el nuevo concepto no ha sido problematizado más que en algunos trabajos parciales (Barranquero, 2011, 2012; Chaparro, 2009; Cimadevilla, 2004; Herrera, 2008), por lo que sigue siendo ambiguo y problemático (Wilkins, 2009), además de una noción acrítica con sus fundamentos de partida, como abordaremos a continuación.

\section{Radiografía, un concepto insostenible: comunicación para el cambio social}

Más allá de que hay razones de peso para transitar desde la noción de desarrollo a la de cambio social, el nuevo concepto requiere de un cuestionamiento más profundo, puesto que el campo parece haber reemplazado uno por otro, sin una revisión previa de los términos que componen la ecuación “comunicación para el cambio social”.

En primer lugar, la noción arrastra un sesgo instrumental y mediacéntrico, al entender que la comunicación siempre está al servicio de algo -comunicación para-: el desarrollo, la salud, el medioambiente, la paz, etc. En otras palabras, lo comunicativo se sigue concibiendo no como un proceso, sino como una mera herramienta, medio o soporte útil para un fin. Por otra parte, esta visión subordina la variable comunicación al cambio social en la relación disciplinaria y, en consecuencia, no consigue dar cuenta de su autonomía y potencial interdisciplinar para pensar y articular diferentes áreas del conocimiento. En su defecto, la preposición teleológica y lineal "para" contribuye a acentuar la fragmentación e hiperespecialización propia de las ciencias modernas, sin conseguir asimilar el poder integrador de la comunicación, incluso para avanzar hacia una comprensión integral de los fenómenos sociales y naturales.

En segundo lugar, la noción se adoptó sin haber acometido una revisión previa de su matriz epistemológica. El concepto de cambio social fue utilizado por el funcionalismo norteamericano desde los años cuarenta (algunos autores que lo utilizaron fueron Robert Merton o Paul Lazarsfeld) para referirse a los procesos de movilidad (de clase y estatus) o a la progresiva burocratización y división del trabajo en las sociedades industriales 
complejas. Pero, a decir de Piotre Sztompka (1995), los funcionalistas entendieron el cambio social desde la perspectiva del consenso, infravalorando con ello la existencia del poder y los conflictos. $\mathrm{O}$, como señala Bonilla (en Barranquero, 2009: 594), "No basta pues con acuñar nuevos términos, cuando lo que hay detrás es todo un recorrido en el que (... ) la palabra comenzó a remplazar a otra que entró en desuso, pero (...) sin saber hasta qué punto su proyecto político e ideológico sigue conservando su raíz inicial”.

En tercer lugar, al insistir en la base colectiva de las transformaciones -cambio social-, la etiqueta pierde exactitud, puesto que descuida, entre otras, la importantísima dimensión individual del desarrollo. Expresado de otra manera, el concepto desatiende las múltiples capas de las que se compone la subjetividad humana (Alfaro, 2006), puesto que el cambio es un proceso que puede contribuir a generar capacidades individuales para que los sujetos elijan con libertad la forma en la que quieren vivir (Sen, 1999). Por otro lado, al privilegiar lo social, otras dimensiones (políticas, económicas, culturales, etc.) quedan relegadas a un segundo término:

Las dimensiones políticas son considerablemente críticas en el campo del desarrollo, al dirigir nuestra atención hacia variables como el desarrollo mediático, la gobernanza, el compromiso público o los movimientos activistas. Las condiciones económicas importan en términos de reconocimiento de la importancia de las condiciones materiales, la pobreza, y la justicia distributiva. La identidad cultural también necesita ser incorporada en torno a un marco más amplio que dé cuenta de la producción cultural (Wilkins, 2009).

En cuarto lugar, la expresión cambio social permanece en exceso anclada a la visión tradicional, "antropocéntrica”, del desarrollo. Al definirlo como aquel "proceso de diálogo (... ) a través del cual las personas definen quiénes son (...) y cómo pueden actuar colectivamente para alcanzar sus metas" (Gray-Felder \& Deane, 1999: 8), la noción refuerza la idea de que los seres humanos están de alguna manera "exentos" de "constricciones ecológicas”, gracias a su capacidad de simbolizar (Dunlap \& Catton, 1979: 250). Esta posición ignora el hecho de que el desarrollo debe ser concebido no desde una "razón intervencionista" sobre la naturaleza (Cimadevilla, 2004), sino desde una toma de conciencia de que es imposible rebasar 
los "límites" que nos impone el ecosistema. Frente a estos, no vale cualquier diseño decidido en comunidad, sino que es necesario pensar la disciplina desde una nueva "racionalidad ambiental" (Leff, 1994) que haga frente a los profundos desafíos ecológicos del nuevo siglo, como el del cambio climático. ${ }^{18}$

En quinto lugar, el énfasis en el cambio social recicla el sesgo comunitarista de ciertas aproximaciones participativas al campo, que llegan a mistificar y a romantizar la comunidad y la toma de decisiones comunitaria. Esta crítica fue sugerida por Jesús Martín-Barbero (1987), quien denunció que muchos de los comunicadores latinoamericanos de las décadas de los setenta y ochenta se equivocaron al considerar lo popular como un territorio de supuesta pureza al margen de la cultura masiva, cuando lo alternativo participa en realidad de sus lógicas, y debe ser comprendido desde las múltiples mediaciones entre lo popular-comunitario y lo masivo. En este sentido, la disciplina debe profundizar en su labor de educación ambiental, generando nuevos imaginarios ecológicos frente a los mensajes antiecológicos de las industrias culturales y la publicidad comercial, y su complicidad con la polución ambiental (Maxwell \& Miller, 2012).

Por último, la noción de cambio social apunta siempre a un telos, un fin o una dirección. Y esta remite a la idea de que existe un estado previo de fragilidad que necesita de intervención estratégica para ser mejorado. Sin embargo, "no todo cambio conlleva condiciones que benefician a la población", e incluso "hay cambios que pueden dañar, o incluso matar" (Wilkins, 2009). En este sentido, el nuevo concepto proponía el horizonte utópico del cambio social, pero termina preservando, involuntariamente, el trazado lineal asociado al antiguo desarrollo, que no es otro que el del crecimiento económico basado en una producción ilimitada a expensas de la naturaleza:

Cualquiera que sea el adjetivo que se le dé, el contenido implícito o explícito del desarrollo es el crecimiento económico, la acumulación del

18 Como se reclama en algunos trabajos, desde nuestra perspectiva parciales, que discuten el nuevo concepto de la "comunicación para el desarrollo sostenible” (FAO, 2005; Flor, 2004; Mefalopulos, 2008; Servaes et al., 2012; Servaes, 2013). 
capital con todos sus efectos positivos y negativos que conocemos: competencia sin piedad, crecimiento sin límites marcado por las desigualdades, pillaje sin reparar en la naturaleza (...) el progreso, el universalismo, el dominio de la naturaleza, la racionalidad cuantificante. Esos valores sobre los que reposa el desarrollo y particularmente el progreso, no se corresponden en absoluto con aspiraciones universales profundas. Están relacionadas con la historia de Occidente, tienen poco eco en otras sociedades (Latouche, 2007: 21).

\section{Del cambio social al posdesarrollo y el giro biocéntrico}

Desde mediados de los noventa, Latinoamérica está protagonizando un nuevo tour de force en el ámbito de la teoría crítica mundial, a partir de trabajos como los del denominado "programa de investigación modernidad/ colonialidad"19 -un núcleo de investigadores cohesionados en su búsqueda del cambio social (Escobar, 2003: 52)-, en el que se observan vínculos de amistad similares a los descritos en el caso de la academia comunicacional de los setenta. ${ }^{20}$ Este grupo de pensadores plantea una objeción radical a lo que ellos denominan el proyecto "eurocéntrico" de la modernidad, frente al que postulan la necesidad de articular un "paradigma-otro", que contribuya a bloquear los excesos de la razón moderna, y su colonización del ser, el poder, el saber y la naturaleza en las sociedades latinoamericanas $-y$, en general, de todo el Sur global-, al menos desde las épocas de la Conquista y la Colonización. ${ }^{21}$

Partiendo de la premisa de que la colonialidad es el "lado inevitable de la modernidad” (Mignolo, 2000) y de que la actual globalización es su "radicalización" (Escobar, 2003), el sistema mundial se construye en tor-

19 Adoptado de Lakatos, el concepto de "programa” también es utilizado como sinónimo de agenda común. De hecho, el grupo modernidad/colonialidad se aleja de los estudios poscoloniales de los años setenta y ochenta (Spivak, Bhabha, Said, Guha, Chakravarti) por su énfasis en el colonialismo eurocéntrico sobre Latinoamérica -frente al inglés y el francés de los siglos XIX y XX de los poscoloniales-, su énfasis en la colonialidad como motor de la modernidad y su reflexión acerca de las relaciones de poder que derivan de la matriz cultural "capitalista, moderna, patriarcal y colonial del sistema-mundo" (Castro-Gómez \& Grosfoguel, 2007: 17).

20 Este grupo está liderado por teóricos como Walter Mignolo, Aníbal Quijano, Arturo Escobar, Edgardo Lander, Nelson Maldonado-Torres, Ramón Grosfoguel, Daniel Mato, Enrique Dussel, Boaventura De Sousa Santos o Catherine Walsh.

21 Mignolo (2010) considera que la matriz colonial del poder engloba el control de la economía, la cultura, la naturaleza y los recursos naturales, el género y la sexualidad, y, por último, la subjetividad y el conocimiento. 
no a una particular "geopolítica del conocimiento", que garantiza al Norte el acceso y la posibilidad de "enunciar", ${ }^{22}$ hasta invisibilizar toda epistemología o cosmovisión que no cumpla con su ideario racionalista y expansivo, o el "pensamiento periférico" del "otro colonial", al que ha referido Quijano (2000). A decir de los autores, el saber moderno/colonial no ha conseguido dar cuenta de la enorme complejidad, dinamismo y excepcionalidad que hay en el mundo, $y$ ha instaurado, en su lugar, un nuevo régimen de representación y enunciación, basado en la idea occidental de "totalidad"23 (Mignolo, 2010), cimentado en pares de opuestos organizados de forma jerárquica y excluyente: Norte/Sur, Occidente/Oriente, moderno/tradicional, desarrollado/subdesarrollado, hombre/mujer, heterosexual/otras sexualidades, cultura/naturaleza, ciudad/campo, humano/no humano, etc.

La reflexión en torno al "posdesarrollo" es otro de los ejes de trabajo de los autores. ${ }^{24}$ En esta línea, Arturo Escobar $(1996,2000)$ argumenta que el binomio modernidad/colonialidad provocó que el sistema de cooperación se instituyese como un nuevo régimen imperialista de enunciación, en el que un Norte privilegiado califica o "nombra" como "subdesarrolladas" a las comunidades y regiones del Sur. Las propias teorías de la dependencia contribuyeron a reforzar este esquema, al legitimar el desarrollo como categoría cultural. Desde entonces, y a partir de una tarea de "desprendimiento" (de-linking) con respecto a "las vinculaciones de la racionalidadmodernidad con la colonialidad" y "con todo poder no constituido en la decisión libre de las gentes” (Quijano, 1992: 447), el grupo invita a pensar una nueva teoría "desde/del Tercer Mundo", pero no solo para sí mismo, sino también para el Norte, o, en otras palabras, Latinoamérica como un nuevo "locus de enunciación" (Mignolo, 2000: 209), desde el cual es posible edificar epistemologías desde "el otro lado de la línea” o desde los límites mismos de la exclusión:

22 Se puede percibir en sus planteamientos una sugerente revitalización del pensamiento de Foucault.

23 De hecho, el grupo critica la tendencia a la totalidad de las grandes narrativas de la matriz eurocéntrica (cristianismo, comunismo, liberalismo, etc.), desde la consideración de que "nadie detenta la razón y verdad absoluta y, por lo tanto, ninguna persona (ningún colectivo, ninguna iglesia, ni ningún gobierno) de izquierda o de derecha, puede ofrecer una solución para la población del planeta en su conjunto" (Mignolo, 2010: 30),

24 Las perspectivas posdesarrollo (Escobar, 2000; Sachs, 1992) fueron propuestas por primera vez en los años ochenta y han sido abordadas por autores de distintos contextos geográficos, como Arturo Escobar, James Ferguson, Ivan Illich, Serge Latouche, Gilbert Rist, Wolfgang Sachs, Gustavo Esteva, Majid Rahnema, Helena Norberg-Hodge y Vandana Shiva. 


\begin{abstract}
El pensamiento posabismal (...) no es un pensamiento derivado; implica una ruptura radical con los modos occidentales modernos de pensar y actuar. En nuestro tiempo, pensar en términos no-derivados significa pensar desde la perspectiva del otro lado de la línea, precisamente porque el otro lado de la línea ha sido el reino de lo impensable en la modernidad occidental (De Sousa Santos, 2010: 32).
\end{abstract}

En este proceso de descentralización de los saberes, el nuevo programa está llevando a cabo una intensa labor de rescate o revitalización de autores y tradiciones propias del pensamiento latinoamericano -Martí, Bolívar, Sarmiento, Freire, etc.-, además de reivindicar ciertos conocimientos excluidos de la modernidad -de los movimientos sociales, los indígenas, las mujeres, las clases oprimidas, etc.-, que se alejan de la racionalidad positivista, y su alianza con el sistema capitalista (Quijano, 2000).

Con algunas excepciones (De Souza Silva, 2011; Barranquero \& Sáez, 2012; Torrico, 2013), los debates en torno a la modernidad/colonialidad no han sido incorporados en el pensamiento comunicacional, con lo que la disciplina "se ha quedado anclada a una perspectiva ingenua y despolitizada de hibridaciones, que parece ignorar los flujos desiguales de poder, el persistente embate de la colonialidad con sus diversos ejes de discriminación y sus discursos eurocéntricos de legitimación” (Valencia, 2012: 162-163). Por su parte, el programa modernidad/colonialidad sigue manejando una visión en exceso simplista y funcionalista de la comunicación, puesto que tiende a observar a los medios como estructuras cerradas -o meros aparatos ideológicos-, y a las audiencias como objetos pasivos, privados de toda habilidad para reinterpretar y resistir los mensajes mediáticos (Valencia, 2012: 162-163).

En otro frente, ${ }^{25}$ Latinoamérica se viene destacando por la construcción de un pensamiento ambiental crítico basado en el rescate de la diversidad cultural y biológica que aún persiste en la región. En su ya extensa tradición teórica, cabe mencionar interesantes ejemplos, como las propuestas de "racionalidad ambiental" (Leff, 1994) y "ecopedagogía" (Gadotti,

25 Hay que destacar que también hay autores del grupo que comienzan a reflexionar, en consonancia con la ecología crítica latinoamericana, que también existe una "colonialidad de la naturaleza", como plantea Edgardo Lander (2000). 
1990) o los estudios sobre "necesidades" y desarrollo a "escala humana" (Max-Neef, 1991, 2005). Desde otros trabajos se insiste en la necesidad de reevaluar el también invisibilizado "conocimiento ecológico tradicional” (Toledo \& Barrera-Bassols, 2008), un concepto que apunta al hecho de que muchas comunidades indígenas, rurales y campesinas del subcontinente han conseguido articular una relación más estrecha y respetuosa con la madre tierra (o Pachamama), desde la asunción de que todas las especies naturales son interdependientes, tal y como propone también el concepto del buen vivir, que se analiza más adelante. En este sentido, cabe mencionar la vitalidad de un renovado movimiento ambientalista de base en la región, que nutre de ideas a los ecólogos y que ha sido descrito como "ecología de los pobres" (Martínez Alier, 2006). De este da buena cuenta la intensa actividad de colectivos como el Movimiento de los Trabajadores Rurales sin Tierra (Movimento dos Trabalhadores Rurais Sem Terra-MST), Vía Campesina, la Red Ecologista Autónoma de la Cuenca de México y otras ecocomunidades, y movimientos para la defensa del Territorio Indígena y el Parque Nacional Isiboro-Secure (Tipnis) en Bolivia, o contra la Iniciativa Yasuní-ITT en la región amazónica ecuatoriana del Parque Nacional del mismo nombre. ${ }^{26}$

Tanto el grupo modernidad/colonialidad como la ecología crítica preconizan entonces un necesario giro biocéntrico y posdesarrollista en los conceptos -desarrollo y cambio social- que, hasta el momento, han dominado en el campo. Los abordajes descritos coinciden en su llamado a re-unir la artificiosa separación moderna entre cultura y naturaleza -que deriva en dicotomías como las de materia/espíritu, mente/cuerpo, urbano/rural, orgánico/inorgánico, etc.- y a intentar estudiar los medios y las tecnologías informativas no como mera plataforma de discurso o representación, sino como un todo holístico, tanto material como cultural, en el que se enmarca la propia vida de los grupos humanos y, por ende, su pensamiento y expresión.

26 Cabe destacar también que la crítica ambientalista e indigenista ha encontrado eco, como veremos, en el nuevo ciclo de las izquierdas latinoamericanas y sus nuevos marcos constituyentes. 


\section{El buen vivir/vivir bien (sumak kawsay/suma qamaña)}

Relacionado con los constructos teóricos anteriores, desde finales de la primera década del siglo América Latina está asistiendo a un fructífero debate en torno a la noción de buen vivir/vivir bien, una cosmovisión ancestral de la población indígena de los Andes, que podría contribuir a enriquecer la teoría de la comunicación (para el cambio social) a partir de la incorporación de la crítica desde la ecología y el posdesarrollo que estamos reclamando, así como con una articulación basada en "las capacidades individuales y el bienestar, la naturaleza, y la distribución de recursos" (Radcliffe, 2012: 240). Esta concepción de algunos pueblos indígenas andinos y amerindios está siendo problematizada en el ámbito de la filosofía, las ciencias sociales, la antropología, el derecho, la política y el propio activismo. ${ }^{27} \mathrm{Sin}$ embargo, el debate aún no ha penetrado en la reflexión comunicacional, a excepción de algunos trabajos precursores, pero parciales, de cuño reciente (Acosta, 2012; ALER, 2012; Arrueta, 2012; Barranquero, 2012; Bravo, 2011; Cabral, 2013; Contreras, 2014; De Souza Silva, 2010, 2011; Díaz Bordenave, 2012; Herrera, 2008).

Con el objeto de introducir el concepto y su relevancia para el campo comunicacional, es preciso establecer unas consideraciones previas a fin de desentrañar su significado y sus implicaciones -epistemológicas y políticas- para el estudio del desarrollo y la comunicación para el desarrollo.

En primer lugar, los significados de la expresión quechua (sumak kawsay) y aimara (suma qamaña) son tan extensos y complejos que resultan prácticamente intraducibles a idiomas como el español o el inglés (Medina, 2011: 39), lo que requiere un acercamiento epistemológico con las debidas cautelas. En segundo lugar, esta noción ha sido incorporada a las constituciones de Ecuador (2008) y Bolivia (2009).

27 Entre los principales autores que vienen problematizando la noción de buen vivir, cabría destacar a Alberto Acosta, Xavier Albó, David Choquehuanca, Pablo Dávalos, Eduardo Gudynas, Fernando Huanacuni, Javier Lajo, Javier Medina, Mario Torres y Simón Yampara. 
En segundo lugar, también es importante considerar que el buen vivir supone hasta el momento un proyecto en curso (Acosta, 2008), aún necesitado de propuestas más concretas para iniciar los procesos de "transición" y "desmercantilización" (Stefanoni, 2012: 14). Esto es patente en las contradictorias políticas públicas que han derivado de los marcos constituyentes antes mencionados, unas políticas que, hasta la fecha, no han respetado in extenso este ideario, al alentar, por un lado, a la preservación de los recursos naturales y, por otro, a la "industrialización endógena” (Acosta, 2009: 51).

En tercer lugar, y partiendo de la premisa de que el buen vivir no es un modelo universal sino más bien un conjunto de cosmovisiones particulares y contextuales (Gudynas, 2011: 443), sus aportes pueden contribuir a enriquecer la reflexión comunicacional, evitando su excesivo apego ideológico a cosmovisiones y sistemas de pensamiento occidentales y coloniales que se basan en la idea de "totalidad" -cristianismo, liberalismo, socialismo, etc.- y del "efecto mágico de hacernos creer que el mundo es lo que esa cosmología dice que es" (Mignolo, 2010: 17).

De hecho, el buen vivir podría ofrecer un marco epistemológico más avanzado y ambicioso que el de las nociones que tradicionalmente han ayudado a redimensionar el concepto originario del desarrollo: humano, sostenible, integral, autocentrado, endógeno, etc. En todo caso, ya han comenzado a tenderse los primeros puentes entre el sumak kawsay y planteamientos derivados de la ecología crítica y las teorías del "decrecimiento", 28 originarios del Norte (como proponen Cacciari, 2010; Garcia, 2012; Latouche, 2007; Marcellesi, 2012; Mosangini, 2012), dado que, más allá de las diferencias, existen entre ellos numerosos puntos en común:

(...) decrecimiento sigue siendo una reacción al 'crecimiento' y el Buen Vivir se desacopla, se desentiende del crecimiento o el decrecimiento. (...) El decrecimiento es un movimiento entendible en los países industrializados, con altos niveles de opulencia, pero no puede ser el objetivo o meta de una alternativa al desarrollo. En nuestras propuestas el

28 A grandes rasgos, el decrecimiento plantea la disminución progresiva y controlada de los actuales niveles de producción/consumo y crecimiento económicos a los que alientan tanto capitalismo como comunismo, a fin de establecer una relación más equilibrada con la naturaleza y reducir los riesgos del cambio climático, como propone también el buen vivir. 
decrecimiento, en vez de ser una meta, es una consecuencia de otros cambios más profundos (Gudynas en Del Viso, 2012: 5).

El vivir bien puede ayudar a completar las limitaciones de los paradigmas dominantes antes descritos, así como ofrecer nuevos inputs a fin de superar su "naturaleza insostenible". A continuación, resumimos algunas de sus principales premisas:

\section{El valor de la naturaleza}

El buen vivir supera las nociones occidentales de "vida buena" o "bienestar", dado que apuesta por una vida en armonía entre los seres humanos y entre estos y la naturaleza. Esto se articula por medio de relaciones de "reciprocidad" basadas en el respeto y en la dignidad de todos los seres vivos, puesto que lo que está en juego es la "vida misma" (Acosta, 2008: 34), la "vida en plenitud" (Dávalos, 2011: 201) o la vida basada en "la comunicación entre humanos y naturaleza” (Walsh, 2010: 18). Desde la comprensión aimara, la noción apela asimismo a significados como los de "vida en paz", "vivir a gusto", "convivir bien", llevar una "vida dulce" o "criar la vida del mundo" con cariño (Farah \& Vasapollo, 2011: 22). Estas concepciones desbordan la concepción tradicional del desarrollo, porque, con su incorporación en las nuevas constituciones, el buen vivir ha contribuido a redimensionar los sentidos políticos, éticos y jurídicos de la naturaleza, puesto que, por primera vez, se la reconoce como objeto portador de valores y como una "tercera generación de derechos", que supone una auténtica "hecatombe para la tradición jurídica francesa-romanista” (Acosta, 2010: 19), que, hasta la fecha, solo consideraba como materia jurídica a los seres dotados de conciencia. ${ }^{29}$ Podemos señalar, por otra parte, que la noción puede contribuir a enriquecer debates emanados en el Norte, como los de la "justicia ambiental", dado que el principio de "relacionalidad" del sumak kawsay también concibe a todos los seres como parte de la misma vida, puesto que "se atan a ella y ponen en marcha un mecanismo de 'relaciones"' (De Marzo, 2010: 165).

29 La Constitución de Ecuador equipara la categoría de naturaleza a la de Pachamama, propia del saber tradicional indígena, e invita en su articulado a respetar su existencia, e incluso a regenerar sus ciclos vitales y restaurar integralmente sus recursos. 


\section{La memoria biocultural sostenible}

El buen vivir colabora en la revalorización de una multiplicidad de legados culturales sostenibles que han logrado sobrevivir desde tiempos ancestrales -superando incluso las dramáticas consecuencias de los procesos de colonización y globalización-, gracias a que se basan en relaciones no utilitarias del ser humano con respecto a la naturaleza. Desde sistemas de códigos esencialmente orales y no sistematizados, el vivir bien establece un diálogo entre las dimensiones materiales y espirituales de la vida, "para devolvernos esa visión multidimensional natural, juntamente con la capacidad de percibir otros aspectos importantes de la vida, más allá de lo estrictamente material, fundamentalmente aquello intangible que también determina nuestras vidas" (Huanacuni, 2010: 34). En otras palabras, el buen vivir da valor a un "campo espiritual que no se puede percibir" pero que sostiene a su vez "el mundo material que se percibe" (Deneulin, 2012:3). Por esto, mientras que la ciencia moderna establece que solo lo medible y lo cuantificable es objeto de conocimiento, los principios multidimensionales que integran el buen vivir, como el ayni andino -traducido, en sentido laxo, como reciprocidad-, apuntan a lógicas de intercambio, cooperación y generación de redes como base para crear conocimiento, comunidad y riqueza: "El énfasis es absolutamente cualitativo. El Ayni produce los valores humanos de la amistad, la alianza, la confianza: las redes sociales que son productoras de humanidad y, a fortiori, de Comunidad" (Medina, 2011: 130). Si tomamos en consideración que "la naturaleza no tiene precio" (Mires, 1996: 49), resulta entonces complejo -cuando no imposible- cuantificar con exactitud el bienestar o el desarrollo. Y en esta línea, los bienes materiales ya no son tan determinantes como el "conocimiento, el reconocimiento social y cultural, los códigos de conductas éticas e incluso espirituales en la relación con la sociedad y la naturaleza, los valores humanos, la visión de futuro, entre otros" (Acosta, 2008: 34). El sumak kawsay alerta entonces de que existen otras formas posibles de alcanzar conocimiento veraz: los sentidos, la corporalidad, las artes, las vivencias, los mitos, etc.

\section{La construcción práctica y comunitaria de los saberes}

El buen vivir apunta a la construcción de saberes operativos, ya que no separa entre teoría y práctica, al modo en que tradicionalmente propone la 
racionalidad moderna. Esta aproximación es comparable al énfasis que la tradición empírica e investigadora en comunicación participativa ha situado en la praxis como el eje principal de la reflexión (Dervin \& Huesca, 2004; Huesca, 2002), a partir de trabajos pioneros como los de Paulo Freire (1969, 1970) y Orlando Fals Borda (1979), que apuntan a que resulta "difícil alcanzar una comprensión coherente y completa de estos sistemas cognitivos separándolos de las actividades y los comportamientos diarios, concretos y prácticos" (Barahona, 1987: 173). Sin embargo, y a diferencia de estos, para el vivir bien la práctica humana es entendida desde su interdependencia con respecto al entorno natural, puesto que "a toda praxis corresponde siempre un corpus de conocimiento (o a toda 'vida' material siempre corresponde una 'vida simbólica')” (Toledo \& Barrera-Bassols, 2008: 70). Desde esta perspectiva, distintos estudios certifican una coincidencia espacial -y no accidentalentre las regiones del mundo que hoy preservan una mayor biodiversidad, y aquellas en las que existe mayor riqueza cultural y lingüística, y en las que predominan poblaciones rurales, indígenas y campesinas. Estas se basan, por otra parte, en sistemas familiares de producción y consumo a pequeña escala (Toledo \& Barrera-Bassols, 2008: 29), en abierto contraste con las economías de gran escala de Occidente, en las que el individualismo competitivo se establece como el único parámetro de crecimiento y desarrollo (Huanacuni, 2010: 13, 53). Esto ratifica la hipótesis, antes sugerida, de que ciertas culturas han conseguido articular una relación de mayor respeto y convivencia con la naturaleza desde sistemas de ideas que incorporan al ser humano como una pieza en relación de continuidad con su entorno. De esta manera, si la cosmovisión moderna prioriza al individuo como único sujeto de derechos y obligaciones, el buen vivir, a través del principio del ayllu, pone el énfasis en la comunidad -entendida como "común-unidad-, lo que ayuda a superar la concepción tradicional occidental de comunidad como estructura social -que ha podido derivar en las posiciones comunitaristas antes criticadas- y desde la compresión de la unidad de la vida entre ser humano y naturaleza. Expresado de otra manera, el buen vivir "incluye las ideas clásicas de calidad de vida, pero desde la visión específica de que el buen-vivir es solo posible en el seno de una comunidad. Más aún, en la mayor parte de las aproximaciones, el concepto de comunidad se entiende desde una visión extensa, a fin de incluir la Naturaleza” (Gudynas, 2011: 441). 


\section{Posdesarrollo}

La nueva noción ayuda a decretar el acta de defunción definitiva al devaluado concepto del desarrollo y a pensar una "comunicación para salir del desarrollo", en el sentido planteado por Erick Torrico (2013). Para el vivir bien no existe la concepción lineal de desarrollo o progreso, tal y como se ha entendido históricamente en Occidente, es decir, como un proceso de transición entre un Estado premoderno o subdesarrollado hacia un estadio ideal de desarrollo, basado, por lo general, en el bienestar material y en la producción y consumo ilimitados de los recursos de la naturaleza. Desde otro ángulo, la propia concepción de pobreza o subdesarrollo tampoco se asocia a la carencia de bienes materiales, de igual manera que la riqueza no se vincula a su abundancia (Acosta, 2008: 34). Para el buen vivir lo principal es el fortalecimiento constante de la vida misma, comunitaria y natural. Esto ayuda a repensar cualquier proyecto emancipador desde una mirada ecológica, puesto que la naturaleza es un determinante fundamental de la calidad de vida. Por ende, el buen vivir contribuye a problematizar la pobreza y la exclusión, ya no en términos económicos, sino desde la valoración de contextos de poder en los que la carencia económica es expresión del control político de la "escasez". Es decir, ya no se trata de resolver la pobreza con los instrumentos propios del capitalismo, sino que es necesario transitar hacia la sustitución o reconfiguración radical del propio sistema, puesto que la pobreza "está en su mismo formato, en su misma episteme" (Dávalos, 2011: 202). La cosmovisión alienta, además, a articular nuevos modelos socioeconómicos en los que el valor de uso anteceda siempre al valor de cambio, y en los que se promuevan patrones de producción y consumo más apegados a las necesidades reales de la población (Farah \& Vasapollo, 2011:23-24). Buenos ejemplos de estas prácticas son las múltiples experiencias de reciprocidad que se vienen dando desde épocas ancestrales y que rompen con la lógica mercantil moderna, ya sea en experiencias de donación, mingas comunitarias, redes de apoyo, trueque, asociaciones cooperativas o las propias fiestas y rituales (Escobar, 2010). Por último, el buen vivir no admite ningún tipo de dominación ni explotación -entre seres humanos o de seres humanos hacia la naturaleza-, a diferencia del "vivir mejor" (que los otros) de la noción hegemónica del desarrollo. En su lugar, estimula una convivencia armónica entre los seres humanos y naturales, sin 
exclusión, desde el respeto y la convivencia, "porque nada ni nadie es útil solo para uno, ni el propósito de las demás formas de existencia es solo el beneficio del ser humano, todo está en una relación complementaria en un perfecto equilibrio" (Huanacuni, 2010: 53).

\section{La comunicación desde el buen vivir}

Para pensar hoy la relación entre comunicación, desarrollo y cambio social es necesario revalorizar el extenso legado cultural sostenible, muchas veces invisibilizado, de las regiones y pueblos de América Latina y el sur global, y avanzar hacia una comprensión crítica, ecológica y poscolonial de estas nociones, y de cómo pueden articularse en la planificación de proyectos y políticas, ya no tanto de desarrollo como de solidaridad, de instancias públicas, privadas y comunitarias (movimientos sociales, $\mathrm{ONG}$, etc.). Por otro lado, la cosmovisión del buen vivir supone un nuevo "fermento" 30 comunicacional surgido desde la "periferia de la periferia mundial” (Tortosa, 2009) y que ayuda a continuar desoccidentalizando los estudios mediáticos a fin de escapar de su matriz cultural capitalista, militar, patriarcal, blanca, heterosexual y masculina, parafraseando a Grosfoguel (2002). Más que sugerir escenarios cerrados, los siguientes párrafos tienen por objeto plantear algunas vías de aproximación a la comunicación desde el concepto de buen vivir.

En primer lugar, el buen vivir ayuda a la comunicación a escapar de los estrechos límites del instrumentalismo (comunicación "para") para concebirse, a la manera que propone Rosa María Alfaro (1993: 27-28), como medio y fin, objetivo y sinergia transformadora. Asimismo, la comunicación desde el buen vivir se configura como un espacio simbólico que intenta resistir y bloquear los marcos culturales insostenibles que derivan, entre otros, de los medios comerciales y la publicidad. Por otra parte, la comunicación contribuye a la necesaria labor de "descolonización epistemológica” de la cosmovisión moderna (Escobar, 2000), a partir de la revaloración de epistemologías sostenibles. Nos referimos de nuevo al rescate de la "memoria biocultural" de los pueblos, y de perspectivas críticas como el decrecimiento, la cultura slow o las filosofías del procomún (commons),

30 Establecemos aquí una metáfora con respecto al ferment in the field o el número especial que la revista Journal of Communication publicó en 1983 a fin de establecer puentes en el conflicto tradicional entre teoría crítica y administrada. 
por mencionar algunos. ${ }^{31}$ En otras palabras, se trata de cimentar una nueva cultura de la sostenibilidad, no desde la fragmentación, sino desde un diálogo entre disciplinas, regiones y grupos humanos, que rebase los saberes esencialistas, totalitarios y colonizadores de la modernidad.

En segundo lugar, adoptar la perspectiva del buen vivir invita a manejar una visión más integral y compleja del campo, dado que la noción apunta a que no todos los pueblos entienden de la misma manera el desarrollo y la comunicación. Si una de las premisas de la disciplina es el respeto a la autonomía y la diversidad de las culturas (Gumucio-Dagron, 2001), es contradictorio entonces seguir insistiendo en la búsqueda de patrones universales de cambio social, puesto que no existe un modelo único de desarrollo y el ser humano no precisa de la comunicación "para" desarrollarse, crecer o evolucionar hacia dirección alguna. Por el contrario, y sin que suponga esto una postura conservadora, muchos territorios y culturas del mundo no necesitan de la comunicación más que para mantener, consolidar y enriquecer sus imaginarios, siempre que estos apunten al equilibrio ambiental y al empoderamiento progresivo - político, económico, social y cultural- de las propias comunidades. Mientras desde las culturas hegemónicas configuradas por la matriz moderna/colonial se tiende a concebir la comunicación como medio para difundir un cambio en las actitudes o el sistema de valores, la idea de que la naturaleza tiene unos "límites" infranqueables lleva a que el único crecimiento posible es el que consigue respetarlos, o incluso regenerarlos, estableciendo una relación de diálogo y reciprocidad entre ser humano y naturaleza. De fomentar esta empresa, la comunicación estaría también contribuyendo a la toma de conciencia de que es necesario actuar desde las auténticas necesidades fisiológicas y psicosociales del ser humano, y la filosofía del "vivir (bien) con menos” (Moreno \& Riechmann, 2007), a la que apuntan ideales como el decrecimiento o el buen vivir.

31 Muy sumariamente, el movimiento slow propone readaptar el tiempo veloz al que impele el capitalismo a los ritmos más densos y pausados de la evolución natural, a fin de mejorar la existencia humana. Por su parte, la reflexión en torno a los comunes plantea que, frente al "cercamiento" del patrimonio natural o la cultura al que inexorablemente tienden Estado y capital, es necesario crear o mantener espacios, procesos y recursos de gestión común, transparente y solidaria. 
En tercer lugar, el buen vivir podría ayudar a desembarazar a la comunicación de todo tipo de adjetivos y etiquetas - para el desarrollo, para el cambio social, para la paz, el medioambiente, etc. - y a hacerla escapar de su posición subordinada ("para”) hasta situarla en el núcleo o, al menos, en condiciones de igualdad en la relación disciplinaria entre comunicación y desarrollo. En este sentido, la comunicación, sin apostillas o ambages, es para el buen vivir sinónimo de diálogo comunitario interhumano y natural, a la vez que recurso simbólico desde el que cimentar relaciones de convivencia, reciprocidad y respeto, no solo entre los seres humanos -como propone el paradigma participativo-, sino entre estos y su entorno natural. De esta manera, el buen vivir complejiza la noción de diálogo, desde una perspectiva que rebasa lo androcéntrico, y que apunta, metafóricamente, a que la naturaleza también "habla" y "escucha" a los seres humanos, aunque no comparta sus códigos. Asimismo, el buen vivir va mucho más allá de un diálogo actual entre culturas en el que, con frecuencia, se establecen "relaciones asimétricas y (neo) coloniales" (Contreras, 2014: 40), al sostener una "búsqueda expresa de superación de prejuicios, el racismo, las desigualdades, las asimetrías (... ) bajo condiciones de respeto, igualdad y desarrollo de espacios comunes" (Ayala, 2011: 57-58).

En cuarto lugar, el buen vivir cuestiona de manera radical el sistema de cooperación actualmente existente, que se concibe desde patrones históricos de intercambio desigual entre Norte y Sur. Desde este ideal, la autocontención y el decrecimiento del Norte se sitúan como un requisito imprescindible para la construcción de modelos sostenibles de bienestar en el sur global, a partir de una mejor distribución de recursos económicos y culturales entre ambos:

Los modelos de cooperación deberían centrar sus ejes de intervención en poner en marcha un ajuste ecológico y social del Norte Global que permita redistribuir con equidad el control y la utilización de los recursos y ecoespacios del planeta entre sus habitantes, así como volver a respetar los límites marcados por la biosfera y las capacidades de regeneración del planeta. Ya no se trataría de enfrentar las carencias del Sur, sino los excesos del Norte (Mosangini, 2011: 248). 
En este sentido, el buen vivir apunta a "cooperar para el postdesarrollo" (Marcellesi, 2012), estableciendo relaciones y solidaridades Norte/Norte, Sur/Sur, Norte/Sur y Sur/Norte desde programas basados en la redistribución de recursos, las necesidades humanas fundamentales, y el ajuste con respecto a los límites que impone la naturaleza.

\section{Conclusiones}

Repensar la comunicación desde el buen vivir es una contribución de las epistemologías del Sur al momento actual de crisis civilizatoria y a los desafíos que esta crisis implica para la investigación e intervención desde una perspectiva comunicativa. Pero estas nuevas epistemologías no se pueden adoptar sin antes prevenir ciertos riesgos. El primero corresponde a una posible idealización del concepto de buen vivir como idea pura, paradigma totalitario o nuevo exotismo para las comunidades desencantadas del Norte. Cuando intentamos traducir conceptualmente la noción, lo hicimos en el sentido de un "tipo-ideal" weberiano, puesto que, en la práctica, es difícil pensar en pueblos originarios de América Latina que se encuentren completamente ajenos a la influencia de los paradigmas de desarrollo de la modernidad occidental, puesto que son comunidades que también forman parte de la lógica de la globalización y de los propios Estados-nación en los cuales se enmarcan. Por otro lado, no hemos problematizado en este artículo acerca de las relaciones de poder que existen al interior de las comunidades que se guían por preceptos como el del vivir bien y que, por supuesto, determinan dominaciones de clase, género, sexualidad, etnia, edad, estatus, etc. Esto último también nos prevendría de recaer en el punto ciego e idealizador del que nos advertía Martín Barbero (1987) con su propuesta de las "mediaciones".

La mejor manera de evitar este riesgo en el futuro puede consistir en implementar planes de investigación de carácter global que establezcan un repertorio de experiencias vivas o en funcionamiento en las que ya existe una articulación entre la comunicación y el paradigma del buen vivir y otras epistemologías sostenibles. Desde este espacio se puede aplicar el ejercicio que propone el concepto de "traducción" de Boaventura de Sousa Santos, que invita a construir una nueva razón, cosmopolita, 
descentrada y basada en la experiencia y en el presente, antes que en las grandes narrativas o los entramados de la abstracción: "La traducción es el procedimiento que permite crear inteligibilidad recíproca entre las experiencias del mundo, tanto las disponibles como las posibles (...) se trata de un procedimiento que no atribuye a ningún conjunto de experiencias ni el estatuto de totalidad exclusiva ni el estatuto de parte homogénea" (2005: 175). Se trata, por otra parte, de descolonizar la comunicación desde la conexión con la "sociología de las emergencias" que propone el mismo autor, un proyecto orientado a transformar las ideas "imposibles" en "posibles", haciendo emerger la experiencia desperdiciada, negada o invisibilizada como fuente de conocimiento por el pensamiento moderno occidental. Esto no es puro voluntarismo, puesto que concebimos que lo que emerge como "posible" tiene que ver con el rescate e impulso de muchas experiencias actualmente existentes.

La referencia a la necesaria "traducción" e inteligibilidad recíproca nos adentra en las posibilidades de emplear la comunicación para abrir un diálogo global y multicultural entre los marcos epistemológicos sostenibles (procomún, decrecimiento, slow, buen vivir, etc.), que actualmente se discuten en el Norte y el Sur del planeta, porque la comunicación es, precisamente, lo que marca la diferencia entre una aproximación "intercultural" y la aproximación "multicultural" hoy dominante: "El multiculturalismo hace aparecer el intercambio pacífico de un espacio común entre varias culturas, pero la interculturalidad es el intercambio proactivo de conocimiento y valores a través de la comunicación" (Gumucio-Dagron, 2014: 109).

De esta manera, ya se están abriendo puentes entre la cosmovisión del buen vivir y paradigmas originados en Occidente, como podría ser el caso del "derecho a la comunicación". Acuñado por el francés Jean D’Arcy en 1969 en los debates del Nomic/McBride, el concepto

\footnotetext{
(...) implica una transformación de la mirada liberal e individualista en la que hasta el momento se han basado los derechos a la Libertad de Prensa y a la Información (...). No puede estar subordinado a las tendencias del mercado, es por eso que este derecho exige también redistribución y democratización del acceso, producción y los canales por donde circula la comunicación (Acosta, 2012: 7).
} 
En este sentido, en la nueva Constitución de Ecuador (2008), el propio derecho a la comunicación se enmarca en el proyecto más amplio del buen vivir:

Entre los logros constitucionales alcanzados consta el reconocimiento de la comunicación, información y cultura como derechos humanos fundamentales y articuladores del Régimen del Buen Vivir. De hecho, la comunicación se incorpora transversalmente en todo el texto constitucional. Varios artículos relacionados con plurinacionalidad, educación, cultura, salud, participación social, derechos de los pueblos indígenas, de la niñez, las mujeres, las personas con discapacidades, entre otros, hacen referencia a la comunicación, el acceso a los medios, la información, la libertad de expresión (ALAl, 2013: 238).

Otro buen ejemplo es el proyecto ecuatoriano del buen conocer de FLOK Society, que propone un "cambio de matriz productiva" desde el diálogo entre el buen vivir y los comunes (commons), que es una filosofía que deriva fundamentalmente del Norte. ${ }^{32}$

Ya en el ámbito de nuestra disciplina, se puede citar como ejemplo de diálogo multicultural la inagotable fuente de inspiración del repertorio global de prácticas de comunicación alternativa sistematizadas en la Encyclopedia of Social Movement Media, que anima también a la "mutua inteligibilidad" entre experiencias de comunicación de los movimientos sociales, si tenemos en cuenta que todas estas experiencias son "vehículos centrales con los cuales la sociedad civil global puede concebir colectivamente soluciones (...), realizar un seguimiento de sus trayectorias y evaluarlos, desde lo más local e inmediato hacia lo internacional y el largo plazo" (Downing, 2010: 26).

32 Ver: http://floksociety.org/category/minga-en-red/ 


\section{Referencias}

Acosta, A. (2008). El buen vivir, una oportunidad por construir. Revista Ecuador Debate, 75, 33-48.

Acosta, A. (2010). El Buen Vivir en el camino del post-desarrollo. Una lectura desde la Constitución de Montecristi. Quito: Friedrich Ebert Stiftung, FES-ILDIS.

Acosta, A. (2013). El Buen Vivir. Sumak Kawsay, una oportunidad para imaginar otros mundos. Barcelona: Icaria.

Acosta, A. M. (2011). La comunicación un derecho necesario para el Buen Vivir. Recuperado de http://www.inredh.org/archivos/boletines/ comunicacion_derecho_buenvivir.pdf (Fecha de consulta: enero 17 de 2013).

ALAI (2013). Ecuador: conquistas constitucionales que no aterrizan. En León, O. (Coord.), Democratizar la palabra. Movimientos convergentes en comunicación. Quito: ALAI.

Albó, X. (2008). Buen Vivir = Convivir Bien. CIPCA Notas, 217.

Albó, X. (2011). Suma qamaña = convivir bien. ¿Cómo medirlo? En Farah, I. H. \& Vasapollo, L. (Coords.), Vivir bien: ¿paradigma no capitalista? (39-65). La Paz: Cides-UMSA, Universidad de Roma La Sapienza y Oxfam.

Alfaro, R. M. (1993). Una comunicación para otro desarrollo: para el diálogo entre el norte y el Sur. Lima: Calandria.

Alfaro, R. M. (2006). Otra brújula. Innovaciones en comunicación y desarrollo. Lima: Calandria. 
Ayala, E. (2011). Interculturalidad. Camino para el Ecuador. Quito: Confederación Nacional de Organizaciones Campesinas, Indígenas y Negras (Fenocin).

Arrueta, C. (2012). Procesos comunicacionales globales. Acerca de las tensiones desde el paradigma del 'Vivir Bien' y el pensamiento neoliberal. Razón y Palabra, 79.

Barahona, R. (1987). Conocimiento campesino y sujeto social campesino. Revista Mexicana de Sociología, 49, 167-190.

Barranquero, A. (2009). Latinoamérica en el paradigma participativo de la comunicación para el cambio. Málaga: Universidad de Málaga.

Barranquero, A. (2011). El espejismo de la comunicación para el cambio social. Radiografía de un concepto insostenible. Hacia una comunicación de cambio ecosocial. En Pereira, J. M. \& Cadavid, A. (Eds.), Comunicación, desarrollo y cambio social: Interrelaciones entre comunicación, movimientos ciudadanos y medios (81-100). Bogotá: Pontificia Universidad Javeriana y otros.

Barranquero, A. (2012). De la comunicación para el desarrollo a la justicia ecosocial y el buen vivir. CIC Cuadernos de Información y Comunicación, 17, 63-78.

Barranquero, A. \& Sáez, C. (2012). Teoría crítica de la comunicación alternativa para el cambio social. El legado de Paulo Freire y Antonio Gramsci en el diálogo Norte-Sur. Razón y Palabra, 80.

Beigel, F. (2006) Vida, muerte y resurrección de las "teorías de la dependencia”. Levy, B. et al., Crítica y teoría en el pensamiento social latinoamericano (287-326). Buenos Aires: Clacso.

Beltrán, L. R. (1974). Communication research in Latin America: The blindfolded inquiry? International Scientific Conference on Mass Com- 
munication and Social Consciousness in a Changing World, Karl Marx Universität. Leipzig, Alemania, 17-20 de septiembre.

Beltrán, L. R. (1976). Alien premises, objects and methods in Latin America communication research. Communication Research, 3(2), 107-134.

Beltrán, L. R. (1979). Farewell to Aristotle: "horizontal communication”. International Commission for the Study of Communication Problems, 48. París: Unesco.

Beltrán, L. R. (1993). Comunicación para el desarrollo en Latinoamérica: una evaluación al cabo de cuarenta años. IV Mesa Redonda sobre Comunicación y Desarrollo. Lima, Instituto para América Latina, 23-26 de febrero.

Beltrán, L. R. (2007). Comunicación para la democracia en Iberoamérica: memoria y retos de futuro. Telos, 72, 20-30.

Bravo, R. (2011). La comunicación para el desarrollo en las políticas públicas ecuatorianas: retrospectiva y situación actual. Mesa Redonda Ecuatoriana sobre Comunicación para el Desarrollo. Quito, 24 de febrero.

Cabral, M. C. (2013). Aportes de la comunicación popular al Buen Vivir. Tram [p] as de la Comunicación y la Cultura, 75, 123-130.

Cacciari, P. (2010). Decrecimiento o barbarie. Para una salida no violenta del capitalismo. Barcelona: Icaria.

Cardesín, J. M. (1997). Miseria de la teoría. De la modernización: una revisión de algunos estudios sociológicos sobre el mundo rural contemporáneo. Agricultura y Sociedad, 84, 141-166.

Cardoso, F. H. \& Faletto, E. (1967). Dependencia y desarrollo en América Latina. Buenos Aires: Siglo XXI.

Castro-Gómez, S. \& Grosfoguel, R. (2007). Giro decolonial, teoría crítica y pensamiento heterárquico (prólogo). En Castro-Gómez, S. \& 
Grosfoguel, R. (Comps.), El giro decolonial: Reflexiones para una diversidad epistémica más allá del capitalismo global (9-23). Bogotá: Pontificia Universidad Javeriana.

Chaparro, M. (2009). Comunicación para el empoderamiento y comunicación ecosocial. La necesaria creación de nuevos imaginarios. Perspectivas de la Comunicación, 2(1), 146-158.

Cimadevilla, G. (2004). Dominios. Crítica a la razón intervencionista, la comunicación y el desarrollo sustentable. Buenos Aires: Prometeo.

Contreras, A. (2014). De la comunicación-desarrollo a la comunicación para el buen vivir. Quito: Universidad Andina Simón Bolívar. Recuperado de http://www.uasb.edu.ec/spondylus_conten_site. php?cd=5200\&cd_boletin $=105 \& \mathrm{sec}=$ PAP (Fecha de consulta: febrero 13 de 2014).

Curran, J. \& Park, M. (Eds.) (2000). De-westernizing media studies. Londres: Routledge.

Dávalos, P. (2009). Reflections on Sumak Kawsay (good living) and theories of development. ALAI. Recuperado de http://alainet.org/ active/33609\&lang=es (Fecha de consulta: enero 17 de 2013).

Dávalos, P. (2011). Sumak Kawsay (La vida en plenitud). En Álvarez, S. (Coord.), Convivir para perdurar. Conflictos ecosociales y sabidurías ecológicas (201-210). Barcelona: Icaria.

Del Viso, N. (2012). Entrevista a Eduardo Gudynas. Boletín Ecos, 19. Recuperado de http://www.fuhem.es/ecosocial (Fecha de consulta: mayo 25 de 2013).

Deneulin, S. (2012). Justice and deliberation about the good life: The contribution of Latin American buen vivir social movements to the idea of justice. Bath Papers in International Development and Wellbeing, 17.

De Marzo, G. (2010). Buen vivir. Para una democracia de la Tierra. La Paz: Plural. 
Dervin, B. \& Huesca, R. (1994). Theory and practice in Latin American alternative communication research. Journal of Communication, 44(4), 53-74.

De Sousa Santos, B. (2005). El Milenio Huérfano. Ensayos para una nueva cultura política. Madrid: Trotta.

De Souza Silva, J. (2010). La pedagogía de la pregunta y el día después del desarrollo. Hacia la educación contextualizada para construir el buen vivir en el mundo rural latinoamericano. Campina Grande, Paraíba, Brasil: Red Nuevo Paradigma para la Innovación Institucional en América Latina. Recuperado de http://pensardenuevo.org/files/2010/10/souza-pedagogia-de-la-pregunta.pdf (Fecha de consulta: abril 7 de 2013).

De Souza Silva, J. (2011). Hacia el 'día después del desarrollo'. Descolonizar la comunicación y la educación para construir comunidades felices con modos de vida sostenibles. Campina Grande, Paraíba, Brasil: ALER 2020. Recuperado de http://recorrido2020.aler.org (Fecha de consulta: abril 7 de 2013).

Díaz Bordenave, J. (1976). Communication of agricultural innovations in Latin America: the need for new models. Communication Research, 3(2), 135-154.

Díaz Bordenave, J. (2012). La comunicación y el nuevo mundo posible. Razón y Palabra, 80.

Di Filippo, A. (2007). La Escuela Latinoamericana del Desarrollo. Cinta Moebio, 29: 124-154.

Downing, J. D. (Ed.). (2010). Encyclopedia of social movement media. Thousand Oaks, California y Londres: Sage.

Dunlap, R. E. \& Catton, W. R. (1979). Environmental sociology. Annual Review of Sociology, 5, 243-273. 
Dutta, M. J. (2011). Communicating social change: Structure, culture, and agency. Nueva York: Taylor \& Francis.

Escobar, A. (1996). La invención del Tercer Mundo. Construcción y deconstrucción del desarrollo. Bogotá: Norma.

Escobar, A. (2000). Beyond the search for a paradigm? Post-development and beyond. Development, 43(4), 11-14.

Escobar, A. (2002). "Worlds and Knowledges Otherwise": The Latin American modernity/coloniality Research Program. Ceisal (Ed.), Cruzando Fronteras en América Latina. Ámsterdam: Cedla. Recuperado de http://www.apse.or.cr/webapse/pedago/enint/escobar03.pdf (Fecha de consulta: junio 09 de 2013).

Escobar, A. (2003). Mundos y conocimientos de otro modo: el programa de investigación de modernidad/colonialidad latinoamericano. Tabula Rasa, 1, 51-86.

Escobar, A. (2010). Una minga para el postdesarrollo. Lugar, medioambiente y movimientos sociales en las transformaciones globales. Lima: Universidad Nacional Mayor de San Marcos.

Esteva, G. (1992). Development. En Sachs, W. (Ed.), The development dictionary. A guide to knowledge as power (6-25). Londres: Zed Books.

Fair, J, E. \& Shah, H. (1997). Continuities and discontinuities in communication and development research since 1958. Journal of International Communication, 4(2), 3-23.

Fals Borda, O. (1979). El problema de cómo investigar la realidad para transformarla. Bogotá: Tercer Mundo.

FAO (2005). Communication for Development Roundtable Report. Focus on Sustainable Development. 9th United Nations Communication for Development Roundtable. Roma, 6-9 de septiembre de 2004. Re- 
cuperado de http://www.fao.org/docrep/008/y5983e/y5983e00. htm (Fecha de consulta: junio 09 de 2013).

Farah, I. H. \& Vasapollo, L. (2011). Introducción. En Farah, I. H. y Vasapollo, L. (Coords.), Vivir bien: ¿Paradigma no capitalista?(11-38). La Paz: Cides-UMSA, Universidad de Roma La Sapienza y Oxfam.

Flor, A. G. (2004). Environmental communication: Principles, approaches and strategies of communication applied to environmental management. Quenzon, Filipinas: University of the Philippines.

Freire, P. (1969). ¿Extensión o comunicación? La concientización en el medio rural. Santiago de Chile: Icira.

Freire, P. (1970). Pedagogía del oprimido. Montevideo: Tierra Nueva.

Gadotti, M. (1990). Pedagogia da terra. São Paulo: Petrópolis.

Garcia, E. (2012). Degrowth and buen vivir (living well): A critical comparison. 3th International Conference on Degrowth for Ecological Sustainability and Social Equity, Venecia, 19-23 de septiembre. Recuperado de http://www.venezia2012.it/wp-content/ uploads/2012/03/WS_20_FP_GARCIA.pdf (Fecha de consulta: agosoto $27 \mathrm{de} 2013$ ).

Gilman, N. (2003). Mandarins of the future: Modernization theory in Cold War America. Baltimore: Johns Hopkins University Press.

Gorz, A. (1994). Capitalism, socialism, ecology. Nueva York y Londres: Verso.

Gray-Felder, D. \& Deane, J. (1999). Communication for social change: A position paper and conference report. Nueva York: Rockefeller Foundation Report. Recuperado de www.communicationforsocialchange. org/pdf/positionpaper.pdf(Fecha de consulta: Agosto 13 de 2013).

Grosfoguel, R. (2002). Colonial difference, geopolitics of knowledge and global coloniality in the modern/colonial capitalist world-system. Review (Fernand Braudel Center), 25(3), 203-224. 
Gudynas, E. (2009). El mandato ecológico. Derechos de la naturaleza y politicas ambientales en la nueva Constitución. Quito: Abya Yala.

Gudynas, E. (2011). Buen Vivir: Today's tomorrow. Development, 54(4), 441-447.

Gumucio-Dagron, A. (2001). Making waves: stories of participatory communication for social change. Nueva York: The Rockefeller Foundation.

Gumucio-Dagron, A. (2006). Son de Tambora. La Iniciativa de la Comunicación. Congreso Mundial de Comunicación para el Desarrollo (WCCD), el Desafío de Babel. Recuperado de www.comminit.com/la/drum beat_155.html (Fecha de consulta: septiembre 4 de 2013).

Gumucio-Dagron, A. (2014). Indigenous communication. From multiculturalism to interculturality. En Wilkins, K. G. Tufte, T. \& Obregon, R. (Eds.), The handbook of development communication and social change (108-124). Malden, Massachusetts: Wiley.

Gumucio-Dagron, A. \& Tufte, T. (Eds.) (2006). Communication for social change anthology: Historical and contemporary readings. South Orange, N. J.: Communication for Social Change Consortium.

Gunaratne, S. A. (2010). De-Westernizing communication/social science research: Opportunities and limitations. Media, Culture \& Socie$t y, 32(3), 473-500$.

Hamelink, C. J. (2004). Did WSIS achieve anything at all? Gazette, 66(34), 281-290.

Herrera, K. (2008). Comunicación para el cambio social. Retos para generar nuevos sentidos para alcanzar la permanente utopía. La comunicación por el cambio social. I Jornadas Hispanoamericanas. La democracia para el cambio social y la educación en valores. Universidad Católica Boliviana y Universidad de Málaga, La Paz, 3-5 de septiembre. 
Hornik, R. C. (1988). Development communication: Information, agriculture, and nutrition in the Third World. Nueva York: Longman.

Huanacuni, F. (2010). Vivir Bien/Buen Vivir. Filosofía, politicas, estrategias y experiencias regionales. Sopocachi, Bolivia: III-CAB.

Huesca, R. (2002). Tracing the history of participatory communication approaches to development: A critical appraisal. En Servaes, J. (Ed.), Approaches to development communication (140-175). París: Unesco.

International Commission for the Study of Communication Problems (1980). Many voices, one world: Communication and society, today and tomorrow. Towards a new more just and more efficient World Information and Communication Order. (The McBride Report). Nueva York y París: Kogan Page, Uniput \& Unesco.

Lander, E. (2000). Ciencias sociales: saberes coloniales y eurocéntricos. En Lander, E. (Comp.), La colonialidad del saber: eurocentrismo y ciencias sociales. Perspectivas latinoamericanas (11-40). Buenos Aires: Clacso.

Latham, M.E. (2000). Modernization as ideology: American social science and "nation building" in the Kennedy era. Chapel Hill, N. P.: University of North Carolina Press.

Latouche, S. (2007). Sobrevivir al desarrollo. De la descolonización del imaginario económico a la construcción de una sociedad alternativa. Madrid: Icaria.

Leff, E. (1994). Ecología y capital: racionalidad ambiental, democracia participativa y desarrollo sustentable. México D. F.: Siglo XXI.

Mansell, R. (1982). The "new dominant paradigm" in communication: Transformation versus adaptation. Canadian Journal of Communication, 8(3), 42-60. 
Manyozo, L. P. (2006). Manifesto for development communication: Nora Quebral and the Los Baños School of Development Communication. Asian Journal of Communication, 16(1), 79-99.

Marcellesi, F. (2012). Cooperación al posdesarrollo. Bases teóricas para la transformación ecológica de la cooperación al desarrollo. Bilbao: Bakeaz.

Marqués de Melo, J. (2007). Entre el saber y el poder: pensamiento comunicacional latinoamericano. Monterrey: Unesco.

Martín-Barbero, J. (1987). De los medios a las mediaciones. Comunicación, cultura y hegemonía. Barcelona: Gili.

Martínez Alier, J. (2005). El ecologismo de los pobres. Conflictos ecológicos y lenguajes de valoración. Barcelona: Icaria.

Mattelart, A. (2013). Por una mirada-mundo. Conversaciones con Michel Sénécal. Temuco: Universidad de la Frontera.

Max-Neef, M. A. (1991). Human scale development: Conception, application and further reflections, with contributions from Antonio Elizalde \& Martin Hopenhayn. Nueva York: The Apex Press.

Max-Neef, M.A. (2005). Del saber al comprender: navegaciones y regresos. Palimpsestvs: Revista de la Facultad de Ciencias Humanas, 5, 93-98.

Maxwell, R. \& Miller, T. (2012). Greening the media. Nueva York: Oxford University Press.

McAnany, E. G. (2012). Saving the world: A brief history of communication for development and social change. Urbana, Chicago y Springfield: University of Illinois.

Medina, J. (2011). Acerca del Suma Quamaña. En Farah, I. H. y Vasapollo, L. (Coords.), Vivir bien: ¿Paradigma no capitalista? (39-64). La Paz: Cides-UMSA, Universidad de Roma La Sapienza \& Oxfam. 
Mefalopulos, P. (2008). Development communication sourcebook. Broadening the boundaries of communication. Washington D. C.: The International Bank for Reconstruction and Development/The World Bank.

Melkote, S. R. \& Steeves, H. L. (1991). Communication for development in the third world: Theory and practice for empowerment. Nueva Delhi, Thousand Oaks y Londres: Sage.

Mignolo, W. (2000). Local histories/global designs: Coloniality, subaltern knowledges, and border thinking. Princeton, N. J.: Princeton University Press.

Mignolo, W. (2010). Desobediencia epistémica. Retórica de la modernidad, lógica de la colonialidad y gramática de la descolonialidad. Buenos Aires: Signo.

Mires, F. (1996). La nueva ecología. El sentido político de la ecología en América Latina. América Latina Hoy, 7, 49-58.

Moreno, J. A. \& Riechmann, J. (2007). Vivir (bien) con menos: sobre suficiencia y sostenibilidad. Barcelona: Icaria.

Mosangini, G. (2012). Decrecimiento y justicia Norte-Sur. O cómo evitar que el Norte Global condene a la humanidad al colapso. Barcelona: Icaria.

Prebisch, R. (1949). El desarrollo económico de América Latina y sus principales problemas. Santiago de Chile: Cepal.

Quijano, A. (1992). Colonialidad y modernidad/racionalidad. En Bonilla, H. (Comp.), Los conquistados. 1492 y la población indígena de las Américas (427-447). Quito: Tercer Mundo-Libri Mundi.

Quijano, A. (2000). Colonialidad del poder, eurocentrismo y América Latina. En Lander, E. (Comp.), La colonialidad del saber: eurocentrismo y ciencias sociales. Perspectivas latinoamericanas (201-246). Buenos Aires: Clacso. 
Radcliffe, S. (2012). Development for a postneoliberal era? Sumak kawsay, living well and the limits to decolonisation in Ecuador. Geoforum, 43, 240-249.

Riaz, S. \& Pasha, S. A. (2012). Development communication in a global perspective. FWU Journal of Social Sciences, 6(1), 8.

Riechmann, J. (2001). Un mundo vulnerable. Ensayos sobre ecología, ética y tecnociencia. Madrid: Catarata.

Rist, G (1997). The history of development: From Western origins to global faith. Londres: Zed Books.

Rogers, E. M. (1962). Diffusion of Innovations. Glencoe, Illinois: The Free Press.

Rogers, E. M. (1976). Communication and development: The passing of the dominant paradigm. Communication Research, 3(2), 213-240.

Rogers, E. M. (1994). A history of communication study: A biographical approach. Nueva York: Free Press.

Rostow, W.W. (1960). The stages of economic growth: A non-communist manifesto. Cambridge: Cambridge University Press.

Sachs, W. (1992). Introduction. En Sachs, W. (Ed.), The development dictionary. A guide to knowledge as power (1-5). Londres: Zed Books.

Samarajiwa, R. (1987). The murky beginnings of the communication and development field: Voice of America and "the passing of traditional society”. En Jayaweera, N. \& Amunagama, S. (Eds.), Rethinking Development Communication (3-19). Singapur: Asian Mass Communication Research and Information Center.

Sempere, J. (2009). Mejor con menos. Necesidades, explosión consumista y crisis ecológica. Barcelona: Crítica.

Sen, A. (1999). Development as freedom. Oxford: Oxford University Press. 
Servaes, J. (1999). Communication for development. One world, multiple cultures. Cresskill, N. J.: Hampton Press.

Servaes, J. (2012). Introduction. En Servaes, J. (Ed.), Communication for development and social change (14-28). Nueva Delhi, Thousand Oaks, Londres y Singapur: Sage.

Servaes, J. (2013). Sustainable development and green communication: African and Asian perspectives. Nueva York: Palgrave.

Shah, H. (2010). Meta-research of development communication studies, 1997-2006. Glocal Times. The Communication for Development Web Magazine, 15.

Shah, H. \& Wilkins, K. (2004). Reconsidering geometries of development. Perspectives on Global Development and Technology, 3(4), 395-416.

Simpson, C. (1993) Mass communication research, counterinsurgency, and scientific reality. En Solomon, W. S. \& McChesney, R. W. (Eds.), Ruthless criticism: New perspectives in U.S. communication history (313-348). Minneapolis: University of Minnesota Press.

Sparks, C. (2007). Globalization, development and the mass media. Londres: Sage.

Stefanoni, P. (2012). ¿Y quién no querría “vivir bien”? Encrucijadas del proceso de cambio boliviano. Crítica y Emancipación. Revista Latinoamericana de Ciencias Sociales, 7, 9-26.

Stevenson, R. L. (1988). Communication, development and the third world: The global politics of information. Nueva York: Longman.

Sztompka, P. (1995). Sociología del cambio social. Madrid: Alianza.

Toledo, V. M. \& Barrera-Bassols, N. (2008). La memoria biocultural. La importancia ecológica de las sabidurías tradicionales. Barcelona: Icaria. 
Torrico, E. R. (2013). Una comunicación para salir del desarrollo. Quórum Académico, 10(2), 363-376.

Tortosa, J. M. (2009). El futuro del maldesarrollo. Obets Revista de Ciencias Sociales, 4, 67-83.

Tunstall, J. (1977). The media are American: Anglo-American media in the world. Nueva York: Columbia University Press.

Valencia,J. C. (2012). Mediaciones, comunicación y colonialidad: encuentros y desencuentros de los estudios culturales y la comunicación en Latinoamérica. Signo y Pensamiento, 30(60), 156-165.

Walsh, C. (2010). Development as Buen Vivir: Institutional arrangements and (de)colonial entanglements. Development, 53(1), 15-21.

Wang, G. (Ed.) (2010). De-Westernizing communication research: Altering questions and changing frameworks. Nueva York: Routledge.

White, R.A. (1989). La teoría de la comunicación en América Latina. Una visión europea de sus contribuciones. Telos, 19, 43-54.

Wilkins, K. G. (2009). What's in a name? Problematizing communications shift from development to social change. Glocal Times, 13.

Wilkins, Karin G. (2014). Emerging issues in communicating development and social change. En Wilkins, K., Tufte, T. y Obregón, R. (Eds.), The handbook of development communication and social change (138144). Oxford: Wiley.

Wilkins, K. G. \& Moody, B. (2006). Reshaping development communication: Developing communication and communication development. Communication Theory, 11(4), 385-396.

Wilkins, K. G., Tufte, T. \& Obregón, R. (Eds.) (2014). The handbook of development communication and social change. Oxford: Wiley. 